DOI: $10.5846 /$ stxb202101200211

吴雁南,郑英茂,王䒯,韦博良, 吴初平,沈爱华,陆小康,郑方东,余著成,倪健, 于明坚.弃管杉木林杉木数量与群落物种多样性间的关系.生态学 报,2022,42(3):884-894.

Wu Y N, Zheng Y M, Wang Y, Wei B L, Wu C P, Shen A H, Lu X K, Zheng F D, Yu Z C, Ni J, Yu M J.Relationship between the number of Cunninghamia lanceolata and community species diversity in abandoned Chinese fir forests. Acta Ecologica Sinica, 2022,42(3) :884-894.

\title{
弃管杉木林杉木数量与群落物种多样性间的关系
}

吴雁南 ${ }^{1,2}$, 郑英茂 ${ }^{3}$, 王 莹 $^{2,4}$, 韦博良 ${ }^{2}$, 吴初平 ${ }^{5}$, 沈爱华 6 , 陆小康 ${ }^{7}$, 郑方东 ${ }^{8}$, 余著成 ${ }^{9}$,倪 健 $^{1}$, 于明坚 ${ }^{1,2, *}$

1 浙江师范大学化学与生命科学学院, 金华 321004

2 浙江大学生命科学学院, 杭州 310058

3 浙江九龙山国家级自然保护区管理局, 遂昌 323300

4 浙江大学农业与生物技术学院, 杭州 310058

5 浙江省林业科学研究院, 杭州 310023

6 浙江省林业技术推广总站，杭州 310020

7 䨄江千里岗省级自然保护区管理局, 䓢州 324021

8 浙江乌岩岭国家级自然保护区管理局, 泰顺 325500

9 江山仙霞岭省级自然保护区管理局, 江山 324100

摘要:森林群落物种多样性格局和动态一直是生态学的研究热点,人工林弃管后演替进程中物种多样性变化也很值得研究。杉 木 ( Cunninghamia lanceolata) 作为我国南方林区人工栽培最广、经济价值最高的用材树种之一,其人工林分布面积很大,通常群 落结构简单、物种多样性低,然而群落中杉木数量如何影响植物物种多样性, 迄今缺乏研究。在浙江省自然保护区内, 选择不同 疏伐强度和弃管时间的杉木人工林, 建立了 6 个 $1 \mathrm{hm}^{2}$ 长期动态监测样地, 在 $10 \mathrm{~m} \times 10 \mathrm{~m} 、 20 \mathrm{~m} \times 20 \mathrm{~m} 、 50 \mathrm{~m} \times 50 \mathrm{~m}$ 和 $100 \mathrm{~m} \times$ $100 \mathrm{~m}$ 尺度下, 探究群落物种多样性 (物种丰富度、Simpson 指数、Shannon-Wiener 指数和 Pielou 均匀度指数) 的变化规律, 分析杉 木数量 (多度和相对多度) 对物种多样性的影响。结果显示: 弃管前对杉木林的疏伐强度越高, 演替恢复后的群落物种多样性 越高。相同疏伐程度下,物种多样性随演替时间的延长有先升高后降低的趋势。取样尺度小于 $100 \mathrm{~m} \times 100 \mathrm{~m}$ 时, 杉木数量与物 种多样性呈极显著负相关; $100 \mathrm{~m} \times 100 \mathrm{~m}$ 尺度下仅杉木相对多度与 3 种多样性指数呈显著负相关,杉木多度与各物种多样性均 无显著相关性。群落中杉木相对多度在 30\%以内时,通常拥有较高的物种多样性。

关键词:多度;相对多度;物种多样性;取样尺度;空间分布格局;群落演替

\section{Relationship between the number of Cunninghamia lanceolata and community species diversity in abandoned Chinese fir forests}

WU Yannan ${ }^{1,2}$, ZHENG Yingmao ${ }^{3}$, WANG Ying ${ }^{2,4}$, WEI Boliang ${ }^{2}$, WU Chuping ${ }^{5}$, SHEN Aihua ${ }^{6}$, LU Xiaokang ${ }^{7}$, ZHENG Fangdong $^{8}$, YU Zhucheng ${ }^{9}$, NI Jian ${ }^{1}$, YU Mingjian ${ }^{1,2, *}$

1 College of Chemistry and Life Sciences, Zhejiang Normal University, Jinhua 321004, China

2 College of Life Sciences, Zhejiang University, Hangzhou 310058, China

3 Zhejiang Jiulong Mountain National Nature Reserve Administration Bureau, Suichang 323300, China

4 College of Agriculture and Biotechnology, Zhejiang University, Hangzhou 310058, China

5 Zhejiang Academy of Forestry, Hangzhou 310023, China

基金项目: 国家重点研发计划项目(2018YFC0507203); 国家重点研发计划政府间国际科技创新合作专项(2018YFE0112800); 浙江省科技计划项 目(2017C02028); 国家自然科学基金项目(31870462)

收稿日期:2021-01-20; 网络出版日期:2021-10-11

* 通讯作者 Corresponding author.E-mail: fishmj@ zju.edu.cn 


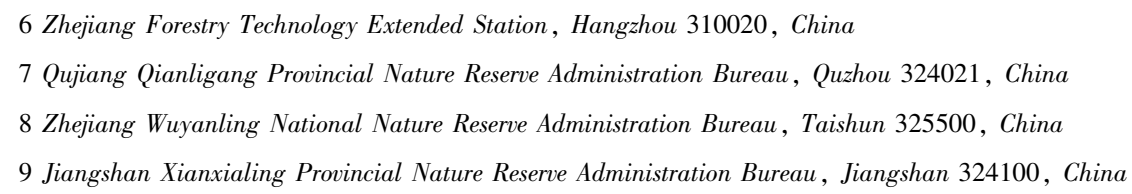

Abstract: The pattern and dynamics of forest community species diversity have always been the research focus of ecology, and the change of species diversity in the succession process of abandoned plantations is also worth studying. The Chinese fir (Cunninghamia lanceolata) is one of the most widely cultivated woods with the highest economic value in the southern forest region of China. This plantation usually has a simple community structure, low species diversity, and poor stress resistance. As for the community in subtropical area, many scholars have studied and discussed the community characteristics of the Chinese fir forests in different forest ages or different thinning intensities, but how the number of the Chinese fir in the community affects the plant species diversity is lack of research so far. In this study, 6 one-hectare longterm dynamic monitoring plots were established at the abandoned Chinese fir forest with different thinning intensities and abandoned time in four nature reserves of Zhejiang Province. Each woody plant with DBH ( diameter at breast height) $\geqslant 1 \mathrm{~cm}$ was investigated, and the species name, DBH, height and coordinates were recorded. The community species diversity (species richness, Simpson index, Shannon-Wiener index and Pielou's evenness index) was investigated at the scales of $10 \mathrm{~m} \times 10 \mathrm{~m}, 20 \mathrm{~m} \times 20 \mathrm{~m}, 50 \mathrm{~m} \times 50 \mathrm{~m}$, and $100 \mathrm{~m} \times 100 \mathrm{~m}$. The distribution pattern and correlation between the number (abundance and relative abundance) of the Chinese fir and species diversity were analyzed. The results showed that the higher the thinning intensity of the Chinese fir forest before abandonment, the higher the species diversity of the community after succession. Under the same thinning intensity, the species diversity firstly increased and then decreased during succession. When the sampling scale was less than $100 \mathrm{~m} \times 100 \mathrm{~m}$, the number of the Chinese fir was negatively correlated with species diversity. Under the scale of $100 \mathrm{~m} \times 100 \mathrm{~m}$, only the relative abundance of the Chinese fir was negatively correlated with the three diversity indices (Simpson index, Shannon-Wiener index and Pielou's evenness index), but there was no significant correlation between the abundance of the Chinese fir and species richness. The values of the three diversity indices in each community were consistent, but had no correlation with species richness. In a word, when the relative abundance of the Chinese fir was less than 30\%, the community usually had relatively high species diversity.

Key Words : abundance; relative abundance; species diversity; sampling scale; spatial distribution ; community succession

杉木 (Cunninghamia lanceolata) 是我国亚热带地区栽培最广、经济价值最高的用材树种。《中国森林资源 报告(2014-2018) 》 ${ }^{[1]}$ 显示,杉木面积与蓄积分别约占全国主要人工林树种的 $1 / 4$ 和 $1 / 3$ 。杉木林也是浙江 省主要的人工林类型之一, 其面积和蓄积量占全省森林的 $21.43 \%$ 和 $28.76 \%$ 。过去栽种杉木往往只追求短 期的生产力与经济利益, 缺乏科学的经营手段, 使得杉木人工林通常结构简单、抗逆性差、生态系统服务功能 低 ${ }^{[3-4]}$ 。2 1 世纪以来,我国林业政策从林业生产为主逐步向林业生态和生产相结合转变, 人工林经营也从追 求短期经济效益转向长期效益与提升生态系统服务质量 ${ }^{[5]}$ 。随着自然保护地数量和面积的扩展、公益林保 护政策的实施, 亚热带地区遗留了大面积的弃管杉木林, 由于伐木历史不一, 群落中杉木种群数量不一, 弃管 后的演替方向也有所差异。

物种多样性是生态系统的重要特征, 为供给、调节和文化科教服务提供支持, 了解物种多样性格局是进行 生物多样性保护和生态系统服务功能提升的重要前提 ${ }^{[6]}$ 。物种多样性存在尺度效应,随取样尺度的选择展 现不同的空间格局 ${ }^{[7-8]}$ 。物种多度的分布也具有尺度效应, 单一尺度难以完整描述种群的分布特征 ${ }^{[9-10]}$ 。 因此, 在研究群落物种多样性与种群数量关系时, 应充分考虑取样的尺度, 以便在适宜的尺度上开展生态保护 和恢复工作 ${ }^{[11]}$ 。

种群多度和相对多度在维持群落物种多样性中发挥重要作用 ${ }^{[12-13]}$, 优势物种的优势地位降低会促进物 
种共存并提高群落物种多样性 ${ }^{[14-15]}$ 。迄今关于杉木林物种多样性的研究, 主要关注杉木纯林不同林分密度 或不同林龄林下物种多样性的变化 ${ }^{[16-17]}$, 适中的杉木多度和合理的树种配置能提高物种多样性和群落稳定 性 ${ }^{[18]}$, 然而关于杉木纯林被不同强度疏伐并弃管后, 杉木数量与物种多样性的研究未见报道。假设人工杉木 林在弃管前杉木疏伐强度越高, 弃管后自然演替时间越长, 群落内杉木的数量 (多度和相对多度) 越低, 物种 多样性越高,且不同取样尺度下杉木数量和物种多样性均表现负相关。因此,本文选择浙江省自然保护区内 6 处弃管杉木林群落,探究不同取样尺度下杉木数量与物种多样性间的关系, 旨在基于生物多样性保护的森 林经营提供科学依据。

\section{1 材料和方法}

\section{1 研究区概况}

研究区位于浙江省 4 个国家级和省级自然保护区内,选取 6 处含杉木数量不同的弃管杉木林并建立 $1 \mathrm{hm}^{2}$ 森林动态监测样地, 具体地点包括九龙山国家级自然保护区内的岩坪和八通, 千里岗省级自然保护区的 大麦源和大坪,乌岩岭国家级自然保护区内上风香和仙霞岭省级自然保护区的龙井坑。所有研究样地在 20 世纪 70-80 年代种植为杉木人工林, 后经杉木疏伐后放弃人工林管理方式 (弃管),在基本保护下自然演替 逐步形成半人工林或次生林。除大坪外,其余样地在弃管前均受到不同强度的杉木疏伐活动,其中龙井坑、八 通岭和大麦源样地约 30 年前受到疏伐, 岩坪和上风香样地约 60 年前受到疏伐 (表 1)。

表 1 研究区样地概况

Table 1 Information for the sampled plant communities in study area

\begin{tabular}{clcccccc}
\hline $\begin{array}{c}\text { 保护区名称 } \\
\text { Nature reserve }\end{array}$ & $\begin{array}{c}\text { 地点 } \\
\text { Site }\end{array}$ & $\begin{array}{c}\left.\text { 经度 } /{ }^{\circ}\right) \\
\text { Longitude }\end{array}$ & $\begin{array}{c}\text { 纬度 } /\left({ }^{\circ}\right) \\
\text { Latitude }\end{array}$ & $\begin{array}{c}\text { 海拔 } / \mathrm{m} \\
\text { Altitude }\end{array}$ & $\begin{array}{c}\text { 弃管年份/a } \\
\text { Abandonment } \\
\text { time }\end{array}$ & $\begin{array}{c}\text { 疏伐强度 } \\
\text { Thinning } \\
\text { intensity }\end{array}$ & $\begin{array}{c}\text { 群落类型 } \\
\text { Community style }\end{array}$ \\
\hline 千里岗 & 大坪 & 118.7735 & 29.2504 & 1041 & 约 30 & 无 & 针叶林 \\
仙霞岭 & 龙井坑 & 118.6617 & 28.2918 & 805 & 约 30 & 低 & 针阔叶混交林 \\
九龙山 & 八通岭 & 118.8480 & 28.3866 & 585 & 约 30 & 低 & 针阔叶混交林 \\
千里岗 & 大麦源 & 118.7667 & 29.2455 & 1050 & 约 30 & 中 & 落叶阔叶林 \\
九龙山 & 岩坪 & 118.8907 & 28.3813 & 747 & 约 60 & 中 & 常绿阔叶林 \\
乌岩岭 & 上风香 & 119.6705 & 27.7056 & 960 & 约 60 & 高 & 常绿阔叶林 \\
\hline
\end{tabular}

\section{2 样地设置及调查方法}

在上述自然保护区范围内选择典型的弃管杉木人工林, 依照热带森林研究中心样地建设技术规范 ${ }^{[19]}$ 建 立 6 个 $1 \mathrm{hm}^{2}$ 森林动态监测样地, 用全站仪打点,每隔 $10 \mathrm{~m}$ 用 PVC 管做固定标记。将 $100 \mathrm{~m} \times 100 \mathrm{~m}$ 的样地划 分成 400 个 $5 \mathrm{~m} \times 5 \mathrm{~m}$ 的小样方, 以 $5 \mathrm{~m} \times 5 \mathrm{~m}$ 为一个调查单元, 对小样方内胸径 $\geqslant 1 \mathrm{~cm}$ 的木本植物进行每木调 查和挂牌标定,测量并记录物种名称、胸径、高度和坐标等数据。

\section{3 数据处理与分析方法}

整理每个 $1 \mathrm{hm}^{2}$ 样地内的物种信息, 分别统计各群落的杉木多度 (杉木个体数)、杉木相对多度 (杉木个体 数占物种总个体数的比例) 和物种多样性, 并绘制 Rank-abundance 曲线。物种丰富度即样方内的物种数目, 是度量物种多样性的代表性指数, 与生态系统的功能密切相关 ${ }^{[20]}$ 。丰富度需结合利用物种相对多度信息, 否 则不能全面地反映群落物种多样性 ${ }^{[21]}$ 。通过 3 种常用物种多样性指数一 Simpson 指数 $(D)$ 、ShannonWiener 指数 $(H)$ 和 Pielou 均匀度指数 $(P)^{[22]}$ 进一步描述物种多样性, 计算公式如下:

$$
\begin{aligned}
D & =1-\sum P_{i}^{2} \\
H & =-\sum P_{i} \ln P_{i} \\
P & =H / \ln S
\end{aligned}
$$


式中, $P_{i}$ 表示物种 $i$ 的相对多度, $S$ 为群落的物种丰富度。

所有 $1 \mathrm{hm}^{2}$ 样地依照 3 种尺度 $(10 \mathrm{~m} \times 10 \mathrm{~m} 、 20 \mathrm{~m} \times 20 \mathrm{~m} 、 50 \mathrm{~m} \times 50 \mathrm{~m})$ 分割为数个连续样方,计算并绘制每 个样方的杉木多度、杉木相对多度和物种多样性的空间分布图。采用 Spearman 秩相关系数检验各尺度下杉 木多度和相对多度与物种多样性间的相关性,对不同数量等级的杉木和物种多样性进行单因素方差分析, 并 用 Scheffe 多重比较法分析组间差异，上述统计分析通过 R 3.2.4 软件完成。

\section{2 结果}

2.1 群落内杉木数量与物种多样性

各 $1 \mathrm{hm}^{2}$ 样地内杉木数量和物种多样性(表 2) 表明, 未曾疏伐杉木的大坪样地, 杉木相对多度最高, 杉木 多度较高,物种多样性显现最低; 其余 5 个曾进行杉木疏伐的样地,物种多样性明显高于杉木林 (大坪)。3 种 多样性指数 $(D 、 H 、 P)$ 在各群落中有一致的变化, 即 $D$ 值最大的群落, 其 $H$ 和 $P$ 也表现最大, 而 $S$ 的大小在各 群落中未显示与上述多样性指数一致的变化规律。

表 2 各样地杉木数量和群落物种多样性

Table 2 The number of Cunninghamia lanceolata and community species diversity in six plots

\begin{tabular}{ccccccc}
\hline $\begin{array}{c}\text { 样地 } \\
\text { Site }\end{array}$ & $\begin{array}{c}\text { 杉木多度/株 } \\
\text { Abundance }\end{array}$ & $\begin{array}{c}\text { 杉木相对多度 } / \% \\
\text { Relative } \\
\text { abundance }\end{array}$ & $\begin{array}{c}\text { Simpson 指数 } \\
\text { Simpson index }\end{array}$ & $\begin{array}{c}\text { Shannon- } \\
\text { Wiener 指数 } \\
\text { Shannon- } \\
\text { Wiener index }\end{array}$ & $\begin{array}{c}\text { Pielou 均匀度指数 } \\
\text { Pielou's evenness } \\
\text { index }\end{array}$ & $\begin{array}{c}\text { 物种丰富度 } \\
\text { Species } \\
\text { richness }\end{array}$ \\
\hline 大坪 & 3108 & 53.84 & 0.70 & 2.24 & 0.50 & 90 \\
龙井坑 & 4662 & 24.23 & 0.92 & 3.29 & 0.68 & 127 \\
八通岭 & 2186 & 15.94 & 0.91 & 2.99 & 0.62 & 124 \\
岩坪 & 656 & 9.01 & 0.94 & 3.31 & 0.68 & 126 \\
大麦源 & 783 & 5.99 & 0.97 & 3.75 & 0.79 & 112 \\
上风香 & 202 & 2.26 & 0.95 & 3.51 & 0.72 & 129 \\
\hline
\end{tabular}

物种等级-丰富度曲线 (图 1) 的宽度反映了群落物 种丰富度,可见大坪样地物种丰富度最低,大麦源样地 物种丰富度中等,其余四样地的物种组成则较为丰富。 曲线的形状反映了群落物种组成的均匀程度, 大坪曲线 陡然下降表明群落内杉木优势种占比最高,且物种均匀 度最低。大麦源曲线在前半数物种等级中展现最高的 物种相对多度,多样性指数也表现最高。上风香曲线的 下降程度相对平缓, 显示其内部物种均匀度相对较高, 岩坪曲线的平坦程度次之, 随后是龙井坑和八通岭曲 线,物种分布的均匀程度依次降低。

2.2 不同尺度下杉木数量和物种多样性的空间分布 绘制各样地内杉木数量相对多度和多度在 $10 \mathrm{~m} \times$ $10 \mathrm{~m}$ (小) $、 20 \mathrm{~m} \times 20 \mathrm{~m}$ (中) 和 $50 \mathrm{~m} \times 50 \mathrm{~m}$ (大) 尺度下 的空间分布(图 2、图 3), 每一行代表同一样地, 由上至

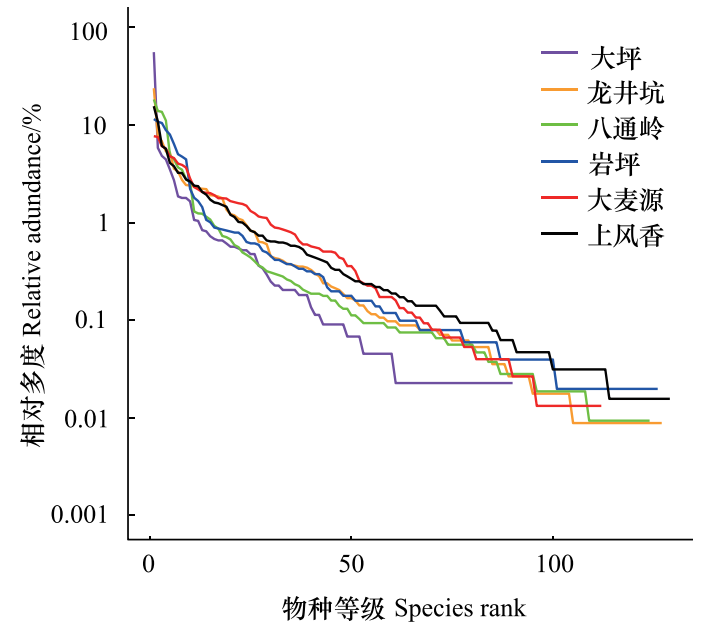

图 1 物种等级-丰富度曲线

Fig.1 Rank-abundance curve 下依次为大坪、龙井坑、八通岭、岩坪、大麦源和上风香 样地。结果显示, 中尺度和小尺度的分布特征较为一致, 即小尺度下杉木数量较高的区域, 在中尺度下也具有 较高的杉木数量。大尺度下杉木数量的分布有时与中小尺度相似, 有时则存在一定差异, 出现弱化局部杉木 数量分布的现象(图 2、图 3), 即大尺度的划分方式掩盖了中小尺度下各小样方间的异质性。 

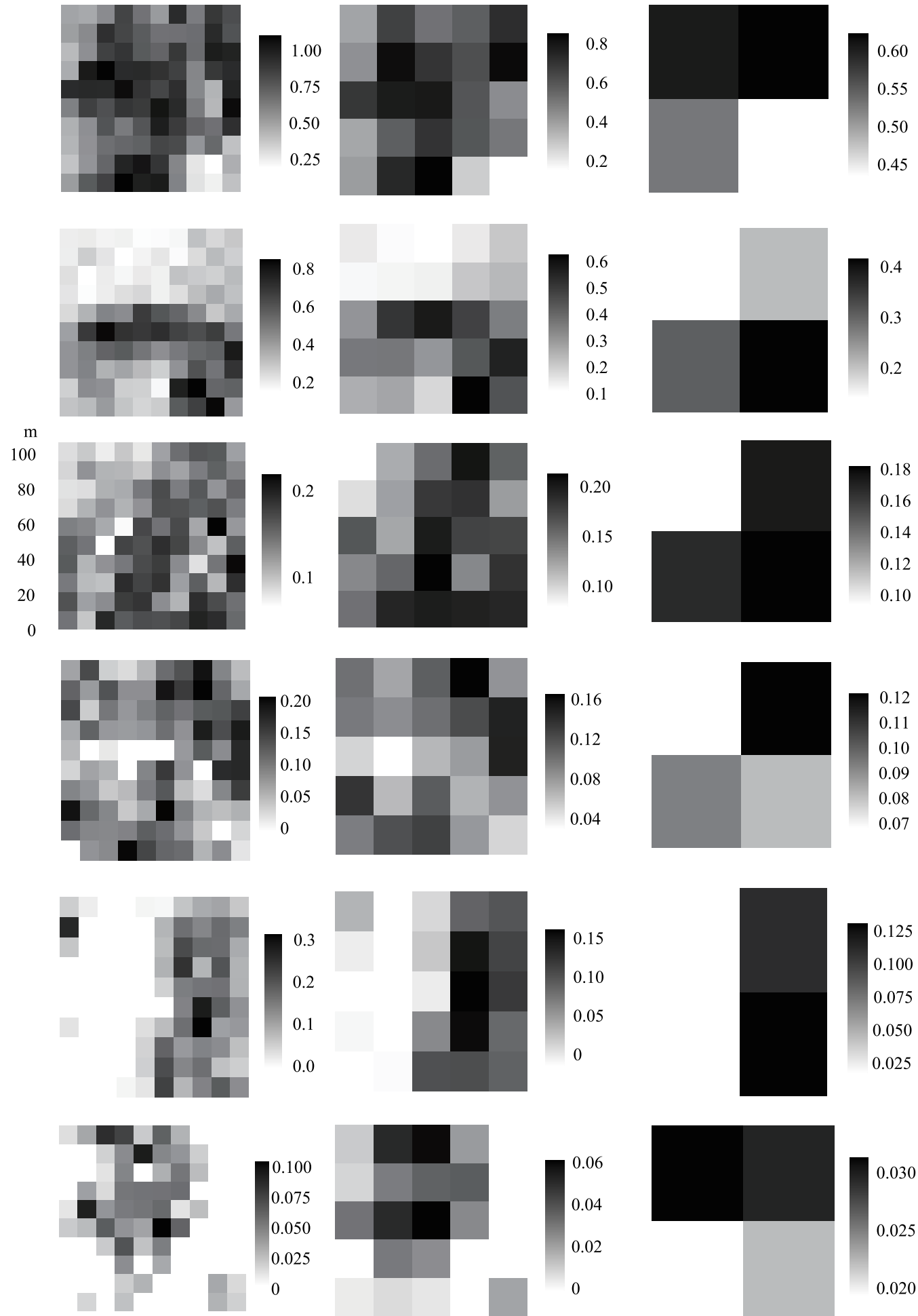

0.030

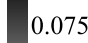

0.050 0.025

$\begin{array}{lllllll}0 & 20 & 40 & 60 & 80 & 100 & \mathrm{~m}\end{array}$

$10 \mathrm{~m} \times 10 \mathrm{~m}$

$20 \mathrm{~m} \times 20 \mathrm{~m}$

$50 \mathrm{~m} \times 50 \mathrm{~m}$

图 2 样地杉木相对多度在 3 种尺度下的分布图

Fig.2 Maps of the relative abundance of Cunninghamia lanceolata in six plots at three sizes

不同尺度下各样地物种多样性分布显示, 3 种多样性指数 $(D 、 H 、 P)$ 在相同尺度下呈现一致的分布格局, 而 $S$ 的空间分布与上述 3 种指数的空间分布表现有所差异, 具体表现为多样性指数高的区域,物种丰富度不 
一定高。对同一物种多样性而言, 中小尺度下具有相近的空间分布, 即小尺度下物种多样性较高的区域在中 尺度下也显示高物种多样性; 而大尺度与中小尺度的空间分布有时会出现差异, 如大尺度下 Simpson 指数 (图 4) 的空间分布忽略了其内部小区块间的差异性。
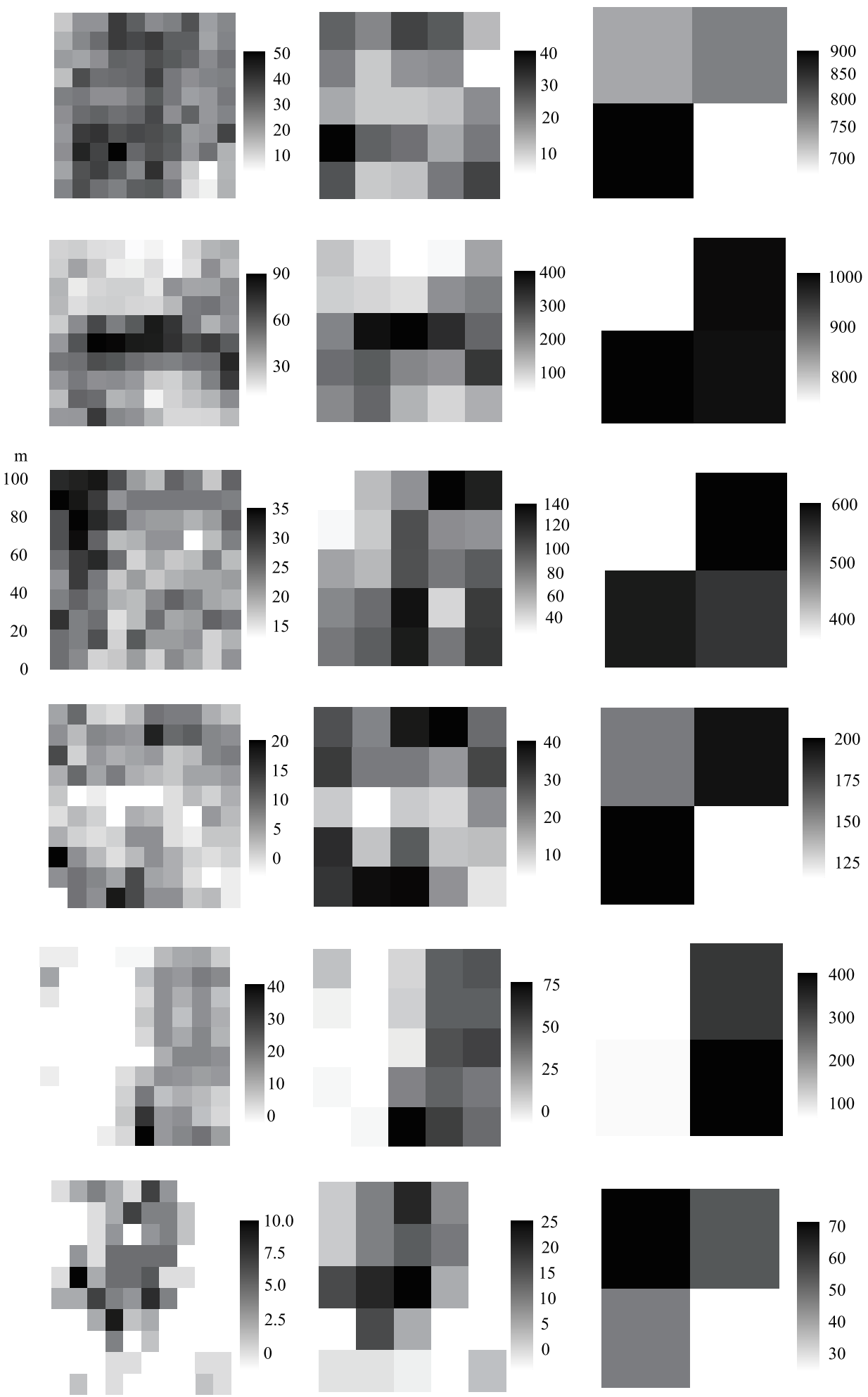

$\begin{array}{lllllll}0 & 20 & 40 & 60 & 80 & 100 & \mathrm{~m}\end{array}$

$10 \mathrm{~m} \times 10 \mathrm{~m}$

$20 \mathrm{~m} \times 20 \mathrm{~m}$

$50 \mathrm{~m} \times 50 \mathrm{~m}$

图 3 样地杉木多度在 3 种尺度下的分布图

Fig.3 Maps of the abundance of Cunninghamia lanceolata in six plots at three sizes

http ://www.ecologica.cn 

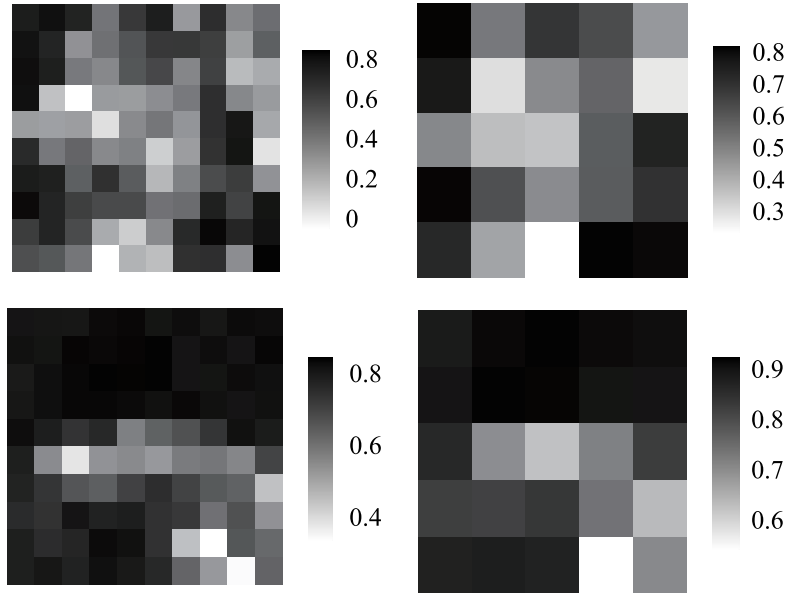

$\mathrm{m}$
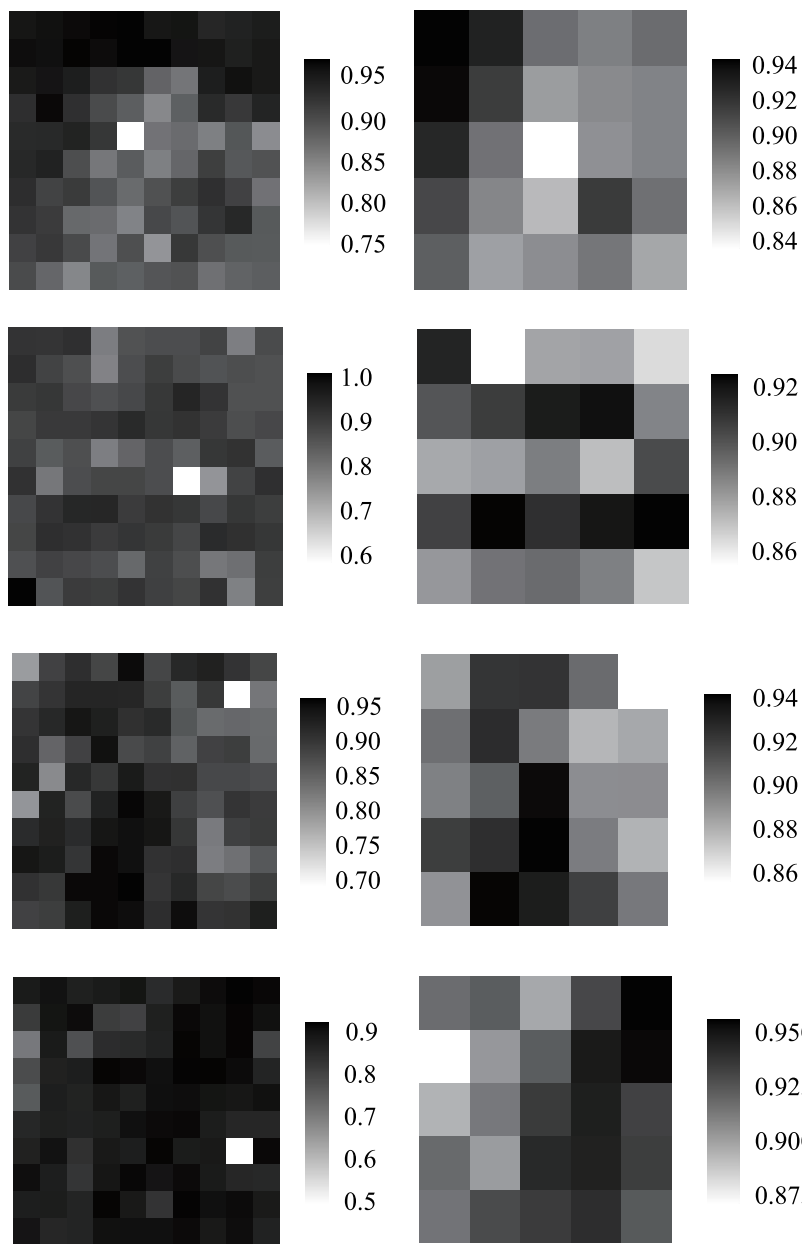

$10 \mathrm{~m} \times 10 \mathrm{~m}$
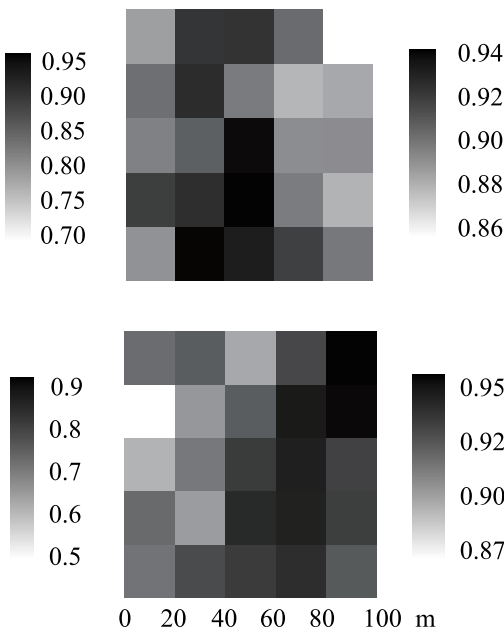

$20 \mathrm{~m} \times 20 \mathrm{~m}$
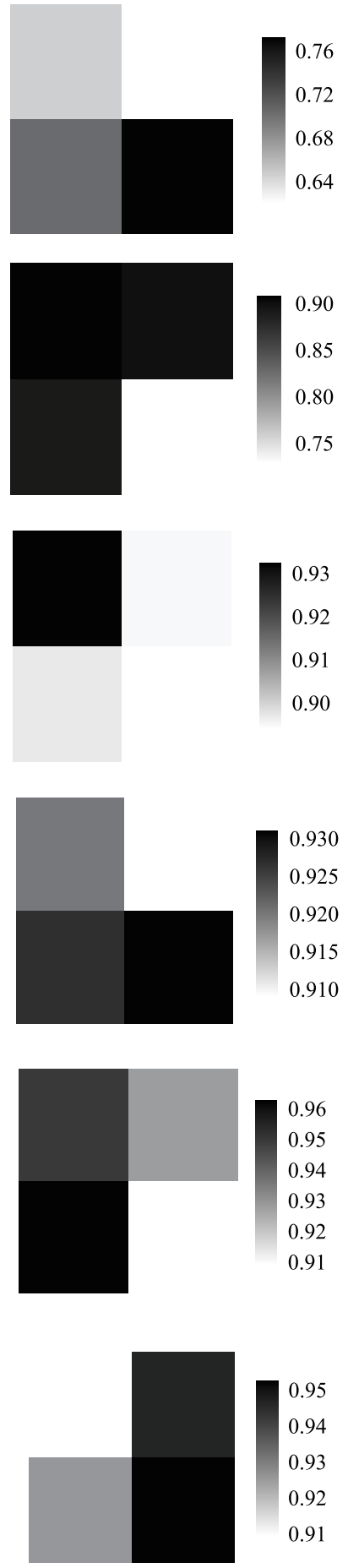

$50 \mathrm{~m} \times 50 \mathrm{~m}$

图 4 样地 Simpson 指数在 3 种尺度下的分布图

Fig.4 Maps of Simpson index in six plots at three sizes

\section{3 不同尺度下杉木数量与物种多样性的关系}

汇总全部样地在各尺度下的杉木数量和物种多样性信息, 发现除 $1 \mathrm{hm}^{2}(100 \mathrm{~m} \times 100 \mathrm{~m})$ 尺度外, 杉木数 量与各物种多样性间均呈极显著的负相关 (图 5)。杉木相对多度与各物种多样性在 $50 \mathrm{~m} \times 50 \mathrm{~m}$ 尺度时具有 最大的秩相关系数; 杉木多度与 $D 、 H$ 和 $P$ 在 $20 \mathrm{~m} \times 20 \mathrm{~m}$ 尺度时展示最强的负相关程度, 与 $S$ 在 $50 \mathrm{~m} \times 50 \mathrm{~m}$ 尺 
度时的负相关最强。整体而言, 杉木相对多度与物种多样性的负相关程度比多度与物种多样性的负相关程 度高。

杉木相对多度或多度与各物种多样性指数间的秩 相关系数在小中大尺度下有相近的变化趋势 ( 图 5), 因 此以 Simpson 指数为代表对物种多样性与不同数量等 级的杉木相对多度和多度进行方差分析 (图 6)。3 种 尺度下,均有杉木相对多度超过 $30 \%$ 后, Simpson 指数 发生显著性降低。其它物种多样性也有同样趋势, 如在 大尺度和小尺度下,杉木相对多度超过 $20 \%, H 、 P$ 和 $S$ 显著降低; 中尺度下,杉木相对多度超过 $10 \%, H 、 P$ 和 $S$ 便显著降低。总而言之,除大尺度下物种丰富度在不同 杉木多度等级间无显著差异外, 在大中小 3 种尺度下， 均有杉木数量越多,物种多样性越低的规律, 当杉木相 对多度低至 30\% 以内时,群落通常拥有较高的物种多 样性。

\section{3 讨论}

3.1 不同疏伐强度和弃管时间对物种多样性的影响 本研究表明,未经疏伐活动的人工杉木林 (大坪样 地)物种多样性最低, 随着自然演替的发生, 逐渐有其 它物种在群落内定居,但物种组成仍不丰富。伴随疏伐 活动的发生,物种丰富度逐渐提高 ${ }^{[23]}$ 。同为疏伐后弃 管约 30 年的 3 个样地中, 受中度疏伐的大麦源样地比

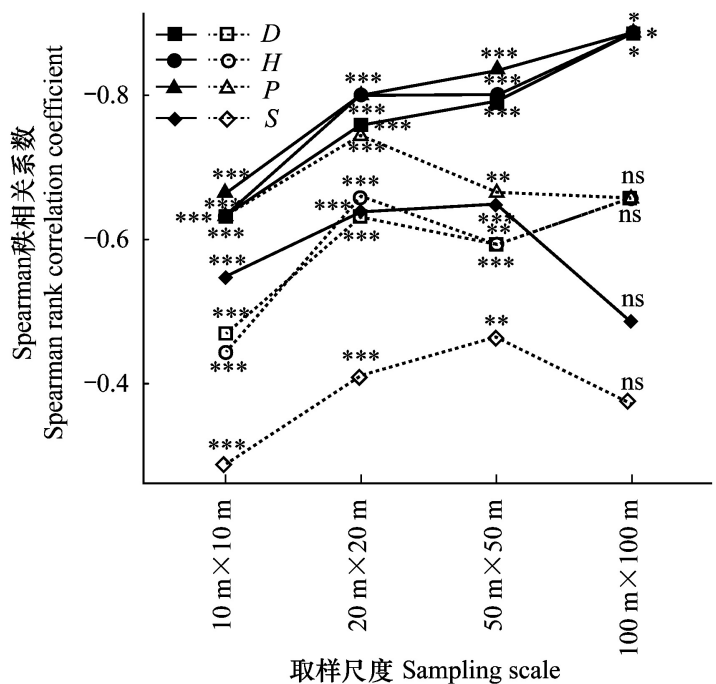

图 5 杉木数量与物种多样性的秩相关系数随尺度变化的关系

Fig.5 The rank correlation coefficient between the number of Cunninghamia lanceolata and species diversity

$D$ : Simpson 指数 Simpson index; $H$ : Shannon-Wiener 指数 ShannonWiener index; $P$ : Pielou 均匀度指数 Pielou's evenness index; $S$ : 物 种丰富度 species richness; ns, $P>0.05 ; * P<0.05 ; * * P<0.01$; $* * * P<0.001$; 黑色线条表示杉木相对多度与物种多样性的关 系,灰色线条表示杉木多度与物种多样性的关系 受轻度疏伐的龙井坑和八通岭样地拥有更高的物种多 样性, 中强度的疏伐既使先锋物种得以快速生长, 又有利于演替后期种的生存 ${ }^{[24]}$, 有助于群落物种多样性的 提高 ${ }^{[25-26]}$ 。中度疏伐后弃管的岩坪样地, 经约 60 年的自然演替, 比相同疏伐强度的大麦源样地内物种多样

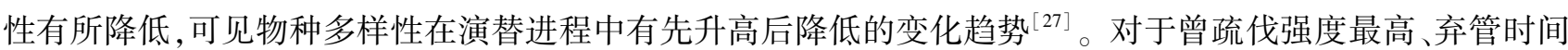
最久, 且已恢复至地带性常绿阔叶林的上风香样地, 森林稀疏程度高但物种组成最为丰富, 群落物种多样性也 较高。

3.2 不同尺度下群落的杉木数量和物种多样性

本研究发现,无论是杉木数量还是物种多样性的空间格局,小尺度和中尺度下通常表现出相对一致的分 布特征, 而大尺度与中小尺度下的分布特征存在一定差异, 即大尺度下的平均化作用会掩盖小尺度下的异质 性信息 ${ }^{[28-29]}$ 。取样尺度过小时, 单一树种的样方比率较高 ${ }^{[30]}$, 而中尺度既与小尺度的分布特征一致, 又能补 充大尺度下因平均化而忽略的小区块间异质性信息。因此, $20 \mathrm{~m} \times 20 \mathrm{~m}$ 尺度能较好地反映出群落物种多样性 和杉木数量的空间分布信息。对不同取样尺度的样带研究也发现, $20 \mathrm{~m}$ 尺度是乔木层物种多样性研究较为 理想的尺度 ${ }^{[30]}$ 。此外,多样性指数 $D 、 H$ 和 $P$ 在大中小尺度下表现一致的空间分布特征,与杉木数量的相关 程度也随尺度增加呈现一致的变化趋势, 这与各群落中近似的物种数量组成比例是分不开的。而 $S$ 在不同尺 度下的变化没有一致的趋势, 可能是由于 $D 、 H 、 P$ 均基于物种数量计算得到, 而物种丰富度是不考虑物种个体 数的指标, 往往取决于生境的异质程度 ${ }^{[31]}$ 。

大量研究表明取样尺度的选择影响物种多样性的评估 ${ }^{[10,32]}$ 。本研究结果表明,杉木数量与物种多样性 的负相关主要体现在 $10 \mathrm{~m} \times 10 \mathrm{~m} 、 20 \mathrm{~m} \times 20 \mathrm{~m}$ 和 $50 \mathrm{~m} \times 50 \mathrm{~m}$ 的取样尺度,在 $100 \mathrm{~m} \times 100 \mathrm{~m}$ 尺度下,杉木相对多 


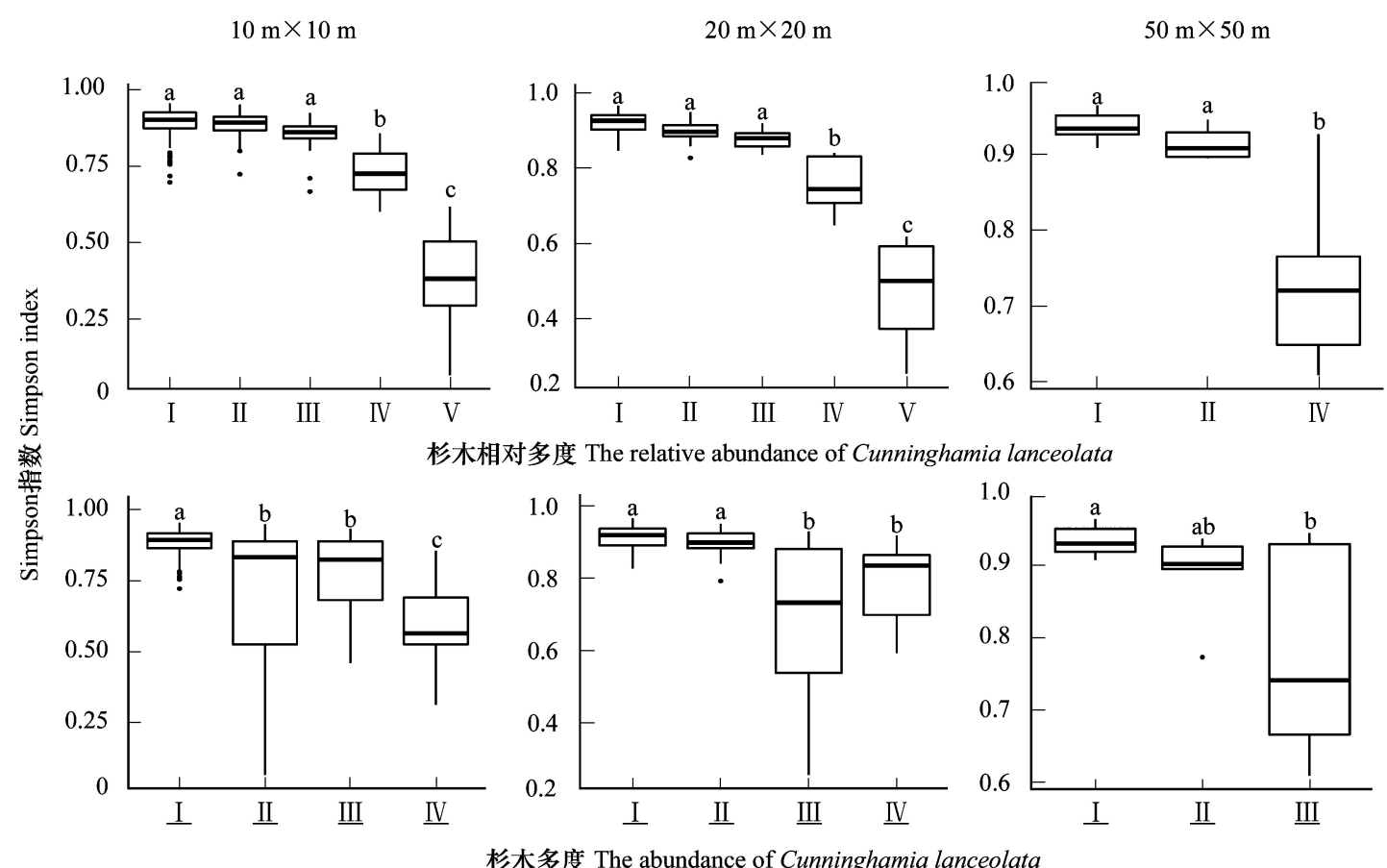

图 6 不同尺度下杉木数量与 Simpson 指数的关系

Fig.6 The relationship between the number of Cunninghamia lanceolata and Simpson index under different scales

IV、II、III、 VI、 V 表示杉木相对多度逐渐增加, 分别代表相对多度为 0-10\%、10\%-20\%、20\%-30\%、30\%-60\%、60\%一 $90 \%$; 不同小写字 母表示组间差异显著是 $(P<0.05)$

度与物种丰富度无显著相关,杉木多度与各物种多样性均无显著相关。类似地研究多度和物种丰富度的秩相 关分析显示,小尺度上两者呈极显著相关,当尺度超过 $100 \mathrm{~m} \times 100 \mathrm{~m}$ 时,两者的相关性不再显著 ${ }^{[33-34]}$ 。相关 性随取样尺度的增加而消失的现象, 可能与尺度增大而引起的生境异质性增加有关 ${ }^{[35-36]}$, 生境越不均匀、越 复杂,物种组成越丰富, 能维持的物种多样性越高 ${ }^{[37-38]}$ 。

\section{3 弃管杉木林经营建议}

不同区域原有种库不同,疏伐后的恢复过程中群落物种组成、多样性提升和自然演替更新速度具有地域 性差异 ${ }^{[39]}$ 。当群落中杉木相对多度在 10\%-30\%之间,杉木数量对降低物种多样性无显著效应。因此, 只有 杉木的数量达到一定阈值后, 才与物种多样性存在显著的负相关。张水松等 ${ }^{[40]}$ 研究表明, 杉木作为常绿阔叶 林中的次要伴生种可给予一定的保留,控制其数量比例约 20\%-30\%较为适宜,这与本研究的结果相似。健 康的森林经营模式需要准确的数据支持和科学理论依赖,比较分析不同研究尺度下物种多样性的变化有实践 意义 ${ }^{[11,41]}$, 共存良好的多个物种比任何单一物种能够更充分地利用群落的资源 ${ }^{[42-43]}$ 。本研究认为, 在 $50 \mathrm{~m} \times$ $50 \mathrm{~m}$ 尺度上,将杉木的相对多度控制在 $30 \%$ 以内,可促进区域内物种多样性的提高。

\section{4 结论}

通过疏伐手段降低人工优势种杉木, 拓展物种生态位, 群落中本土物种得以恢复, 既能保护物种多样性, 又能提高群落的抗逆性和稳定性 ${ }^{[4]}$ 。疏伐后弃管的 $1 \mathrm{hm}^{2}$ 杉木林, 相同自然演替时间内, 疏伐强度越高, 群落 物种多样性高; 相同疏伐强度下,随着群落演替时间的延长,物种多样性有先升高后降低的趋势。多样性指数 $D 、 H$ 和 $P$ 在相同尺度下表现近似的空间分布特征,与杉木数量的相关程度随尺度变化呈现相同趋势, 而物种丰 富度的分布特征和尺度变化与上述 3 种指数不完全相同。在 $10 \mathrm{~m} \times 10 \mathrm{~m} 、 20 \mathrm{~m} \times 20 \mathrm{~m}$ 和 $50 \mathrm{~m} \times 50 \mathrm{~m}$ 尺度下,杉木 数量和各物种多样性间均呈负相关, 维持杉木相对多度在 30\%以内时,群落往往具有较高的物种多样性。 
致谢:感谢浙江大学姚蔡豪、吴倩倩等,自然保护区潘成椿、何振洪等技术人员,以及赖正标、魏湖北、廖长富等 师傅协助进行野外样地建设和植被调查,感谢浙江师范大学刘立斌、饶米德等对本文数据分析和讨论的帮助。

\section{参考文献 (References) :}

［1］国家林业和草原局. 2014-2018 中国森林资源报告. 北京: 中国林业出版社, 2019.

～ 2 ] 王兰芳, 韦新良, 汤孟平. 浙江省杉木林生产力地理分异特性. 浙江农林大学学报, 2019, 36(6): 1107-1114.

[ 3 ] 盛炜粀. 我国人工用材林发展中的生态问题及治理对策. 世界林业研究, 1995, 8(2): 51-55.

[ 4 ] 俞新妥. 论杉木人工林的回归一一从杉木林地力衰退的因果谈杉木林的可持续经营. 世界林业研究, 1999, 12(5): 15-19.

[ 5 ] 刘世荣, 杨予静, 王晖. 中国人工林经营发展战略与对策: 从追求木材产量的单一目标经营转向提升生态系统服务质量和效益的多目标 经营. 生态学报, 2018, 38(1): 1-10.

[ 6 ] Whittaker R J, Willis K J, Field R. Scale and species richness: towards a general, hierarchical theory of species diversity. Journal of Biogeography, $2001,28(4): 453-470$.

[ 7 ] Crawley M J, Harral J E. Scale dependence in plant biodiversity. Science, 2001, 291( 5505) : 864-868.

[ 8 ] Willis K J, Whittaker R J. Species diversity-scale matters. Science, 2002, 295(5558) : 1245-1248.

[ 9 ] Wilson J B, Steel J B, King W M, Gitay H. The effect of spatial scale on evenness. Journal of Vegetation Science, 1999, 10(4) : 463-468.

[10] He F L, LaFrankie J V , Song B. Scale dependence of tree abundance and richness in a tropical rain forest, Malaysia. Landscape Ecology, 2002, $17(6): 559-568$.

[11] Harrison S, Davies K F, Safford H D, Viers J H. Beta diversity and the scale-dependence of the productivity-diversity relationship: a test in the Californian serpentine flora. Journal of Ecology, 2006, 94(1) : 110-117.

[12] Condit R, Hubbell S P, Foster R B. Density dependence in two understory tree species in a neotropical forest. Ecology, 1994, 75(3): 671-680.

[13] Wright J S. Plant diversity in tropical forests: a review of mechanisms of species coexistence. Oecologia, 2002, 130(1) : 1- 14.

[14] Peng Z B, Jiang Y. Density dependence of a dominant species and the effects on community diversity maintainance. Journal of Resources and Ecology, 2016, 7(4): 275-280.

[15] Sapkota I P, Tigabu M, Odén P C. Changes in tree species diversity and dominance across a disturbance gradient in Nepalese Sal (Shorea robusta Gaertn. f.) forests. Journal of Forestry Research, 2010, 21(1) : 25-32.

[16] 贾亚运, 周丽丽, 吴鹏飞, 刘雨晖, 马祥庆. 不同发育阶段杉木人工林林下植被的多样性. 森林与环境学报, 2016, 36(1): 36-41.

[17] 张勇强, 李智超, 厚凌宇, 宋立国, 杨洪国, 孙启武. 林分密度对杉木人工林下物种多样性和土壤养分的影响. 土壤学报, 2020, 57(1)： 239- 250 .

[18] 巢林, 洪滔, 李键, 陈灿, 洪伟, 吴承祯. 中亚热带不同林龄杉木人工林径级结构与林下物种多样性分析. 植物资源与环境学报, 2015, 24(2): 88-96.

[19] Condit R. Research in large, long-term tropical forest plots. Trends in Ecology \& Evolution, 1995, 10(1) : 18-22.

[20] Cardinale B J, Srivastava D S, Duffy J E, Wright J P, Downing A L, Sankaran M, Jouseau C. Effects of biodiversity on the functioning of trophic groups and ecosystems. Nature, 2006, 443(7114) : 989-992.

[21］马克平. 生物群落多样性的测度方法 I $\alpha$ 多样性的测度方法(上). 生物多样性, 1994, 2(3): 162-168.

[22］马克平. 生物群落多样性的测度方法 I $\alpha$ 多样性的测度方法(下). 生物多样性, 1994, 2(4): 231-239.

[23] Griffis K L, Crawford J A, Wagner M R, Moir W H. Understory response to management treatments in northern Arizona ponderosa pine forests. Forest Ecology and Management, 2001, 146(1/3): 239-245.

[24] Sheil D, Burslem F R P. Disturbing hypotheses in tropical forests. Trends in Ecology \& Evolution, 2003, 18(1) : 18-26.

[25] Connell J H. Diversity in tropical rain forests and coral reefs. Science, 1978, 199(4335): 1302-1310.

[26] Molino J F, Sabatier D. Tree diversity in tropical rain forests: a validation of the intermediate disturbance hypothesis. Science, 2001, 294( 5547) : 1702-1704.

[27] Odum E P. The strategy of ecosystem development. Science, 1969, 164(3877) : 262-270.

[28] He F L, Legendre P, Bellehumeur C, LaFrankie J V. Diversity pattern and spatial scale: a study of a tropical rain forest of Malaysia. Environmental and Ecological Statistics, 1994, 1(4): 265-286.

[29] 张忠华, 胡刚, 祝介东, 倪健. 喀斯特常绿落叶阔叶混交林物种多度与丰富度空间分布的尺度效应. 生态学报, 2012, 32(18)： 5663-5672.

[30] 马克明, 叶万辉, 桑卫国, 马克平, 关文彬. 北京东灵山地区植物群落多样性研究X.不同尺度下群落样带的 $\beta$ 多样性及分形分析. 生态 学报, 1997, 17(6): 626-634. 
[31] MacArthur R H, MacArthur J W. On bird species diversity. Ecology, 1961, 42(3) : 594-598.

[32] Kallimanis A S, Halley J M, Vokou D, Sgardelis S P. The scale of analysis determines the spatial pattern of woody species diversity in the Mediterranean environment. Plant Ecology, 2008, 196(1): 143-151.

[33] Wang X G, Hao Z Q, Ye J, Zhang J, Li B H, Yao X L. Spatial variation of species diversity across scales in an old-growth temperate forest of China. Ecological Research, 2008, 23(4): 709-717.

[34] 胡芳, 曾馥平, 杜虎, 彭晚霞, 张芳, 谭卫宁, 宋同清. 桂西北喀斯特常绿落叶阔叶混交林物种多样性分布格局的尺度效应. 生态学报, $2018,38(17): 6074-6083$.

[35] Turner W R, Tjørve E, Hillebrand H. Scale-dependence in species-area relationships. Ecography, 2005, 28(6) : 721-730.

[36] 李艳朋, 许涵, 李意德, 骆土寿, 陈德祥, 周璋, 林明献, 杨怀. 海南尖峰岭热带山地雨林物种多样性空间分布格局的尺度效应. 植物生 态学报, 2016, 40(9): 861-870.

[37] Pianka E R. Evolutionary Ecology. New York: Harper and Row, 1974.

[38] Zhang J Y, Cheng K W, Zang R G, Ding Y. Changes in floristic composition, community structure and species diversity across a tropical coniferous-broadleaved forest ecotone. Tropical Conservation Science, 2014, 7(1) : 126-144.

[39] Zobel M, van der Maarel E, Dupré C. Species pool: the concept, its determination and significance for community restoration. Applied Vegetation Science, 1998, 1(1): 55-66.

[40] 张水松, 詹有生, 陈长发, 敖向阳. 常绿阔叶林树种组成株数比例和材积比例变化规律的研究. 林业科学, 1997, 33(4): 289-298.

[41] Huston M A. Local processes and regional patterns: appropriate scales for understanding variation in the diversity of plants and animals. Oikos, $1999,86(3): 393-401$.

[42] Kelty M J. Comparative productivity of monocultures and mixed-species stands//Kelty M J, Larson B C, Oliver C D, eds. The Ecology and Silviculture of Mixed-Species Forests. Dordrecht: Springer, 1992: 125-141.

[43] Tang C Q, Ohsawa M. Coexistence mechanisms of evergreen, deciduous and coniferous trees in a mid-montane mixed forest on Mt. Emei, Sichuan, China. Plant Ecology, 2002, 161(2): 215-230.

[44] Seiwa K, Eto Y, Hishita M, Masaka K. Effects of thinning intensity on species diversity and timber production in a conifer ( Cryptomeria japonica) plantation in Japan. Journal of Forest Research, 2012, 17(6) : 468-478. 